1 School of Psychology, Swansea University

2 School of Psychology, University of Sussex

3 University College London

4 Department of chemistry, University of Bath

Cite this as: $B M J 2022 ; 376: 0327$ http://dx.doi.org/10.1136/bmj.0327 Published: 09 February 2022

\section{The UK is an international outlier in its approach to covid in children}

\author{
Simon Williams, ${ }^{1,2}$ Susan Michie, ${ }^{3}$ Christina Pagel, ${ }^{3}$ Adam Squires ${ }^{4}$
}

Recent declines in the overall rates of covid-19 in the UK have masked the rapid and steep rise in cases among children. As of 26 January 2022, Office for National Statistics data suggest that nearly $12 \%$ of children in primary school and below (ages 2 to 11), and $6.5 \%$ of children in secondary school (ages 11 to 16), tested positive for covid-19. ${ }^{1}$

Early warnings that a lack of protections for children would lead to a wave of infections from the delta variant, causing disruption to education in the autumn term, were not heeded. ${ }^{2}$ The warnings were reiterated with omicron in December, but again, very little was done to make schools safer. ${ }^{3}$ When schools returned in January 2022, secondary school children (but not primary) were required to wear masks in school. Students in secondary schools (but not primary) were also asked to take a rapid antigen test twice a week at home and to isolate if positive. Children who were contacts of new cases (even household members) were not required to isolate. By the end of January all mask requirements in schools had been dropped and masks were actively discouraged. Just over half of 12-15 year olds had received one dose of vaccine and 5 to 11 year olds were not in general eligible for a vaccine. Carbon dioxide sensors have been distributed to assess ventilation, with advice on ventilation, and 7000 air cleaning filtration units have been made available for the worst ventilated classrooms, but it's clear that classroom ventilation is not enough to stop omicron tearing through schools.

Although children are at much lower risk of experiencing severe illness from covid compared to (particularly older) adults, there are still a number of harms that come from attempting to "live with" high rates of infection in schools. These include record numbers of hospital admissions in children with covid, increasing rates of long covid in children, educational disruption (very high pupil and teacher absenteeism related to infection), and disruption to other sectors (e.g. parents having to stay home from work to care for children who test positive or becoming infected themselves). $4^{-6}$

We have a much better idea now about what works to keep schools open and transmission lower: a combination of vaccination, clean indoor air, testing, contact tracing, isolation and face masks. The problem is that, particularly as far as vaccination and clean air are concerned, we are still yet to see these protections properly put in place for children.

\section{Parents are being denied to choice to vaccinate their 5-11 year olds}

The list of countries that are offering vaccines to children aged 5 and above is growing rapidly. The World Health Organisation recently recommended the reduced dose Pfizer vaccine for children aged 5-12. Research suggests that the Pfizer-BioNTech vaccine is safe and efficacious in children, and the benefits of vaccination for this age group outweigh risks.

US. Centers for Disease Control (CDC) analysis of data for 12-17 year olds suggests it might well protect against PMS-TS as well. ${ }^{7-9}$

Australia and New Zealand have already vaccinated approximately one-third of 5-11 year olds despite only offering them since 10 January 2022 and 17 January 2022 respectively. Key to the quick uptake has been clear messages that covid-19 vaccines are officially recommended for this age group and designed to protect the child, and their families and communities. ${ }^{10}$

The European Union's European Medicines Agency approved the Pfizer/BioNTech vaccine for use in 5-11 year olds in late November, and many countries have now provided a first dose to a growing proportion of children in that age group, including Denmark, where roughly three-in-10 have received two doses. ${ }^{11}$

In the UK, the Medicines and Healthcare products Regulatory Agency (MHRA) approved the Pfizer/BioNTech vaccine for 5-11 year olds on 22 December 2021 and concluded "that there is robust evidence to support a positive benefit-risk profile for this age group." ${ }^{12}$ However, the Joint Committee on Vaccination and Immunisation (JCVI), is still to offer advice as to whether the vaccine should be offered to all children in that age group, rather than just those in a clinical risk group. Moreover, there is no estimate as to when such advice will be published beyond the vague statement that it "will be issued in due course following consideration of additional data." No evidence based justification has provided for this delay. ${ }^{13}$

More transparency over when advice is likely to be provided is necessary and urgent to explain why the UK is an international outlier by not giving parents the choice of whether to vaccinate their child.

\section{Where is the investment in clean air?}

There is growing evidence of the fact that air cleaning measures can help reduce the spread of covid-19 in schools, especially when combined with mask use among teachers and staff. ${ }^{14}$ Air cleaning can be achieved by replacing the stale air that people have breathed out, with fresh outdoor air (ventilation); or by filtering exhaled particles out of the air in the room (filtration, for example, with mobile HEPA units). Studies suggest that combining ventilation with filtration can have added benefits for student attention and health. ${ }^{15}$

Whereas a growing number of countries are making substantial investment in ventilation as part of a 
longer term strategy to provide cleaner indoor air, the UK currently has focused only on "quick fixes to improve ventilation such as being able to open a window," recently providing only 7,000 additional air cleaning units to schools, despite the fact there are more than 300 ooo classrooms in England alone. Many classrooms are likely to need several units to compensate for poor ventilation. ${ }^{16}$

\section{What else should we be doing?}

Despite high and rising rates in secondary schools (currently approximately $7 \%$ according to latest ONS data), schools have been told to remove their mask wearing policy, with the Education Secretary going further arguing they should be "banned." Facemasks should be considered a protection rather than a restriction, keeping children in school learning and teachers in school teaching. Whereas messages around facemasks in the UK, including in schools, have been confusing, other countries have provided a clear and consistent message around their value, for example the United States. We could get further protection by upgrading from cloth or disposable surgical to filtering masks, which should be provided for free as in other countries.

With over one-third of a million children missing school, nearly one-in-10 teachers and school leaders absent and reinfection rates having increased meaning some children have had to isolate multiple times, the UK government's claim to "keep children in the classroom" is disingenuous and overlays a laissez faire approach that in effect leaves children to get infected and miss out on the education and social and other development that school attendance brings. ${ }^{617}$

Competing interests: SM and JD participate in the Scientific Pandemic Influenza Group on Behavioural Science (SPI-B): 2019 Novel Coronavirus (Covid-19) and are members of Independent SAGE. CP is a member of Independent SAGE. AS is Bath University lead for the EPSRC Centre for Doctoral Training in Aerosol Science.

Provenance and peer review: not commissioned, not peer reviewed

Office for National Statistics. Coronavirus (COVID-19) Infection Survey, UK: 28 January 2022. https://www.ons.gov.uk/peoplepopulationandcommunity/healthandsocialcare/conditionsanddiseases/bulletins/coronaviruscovid19infectionsurveypilot/28january2022\#age-analysis-of-thepercentage-of-people-who-had-covid-19

2 Pagel C. Schools-a gaping hole in the English covid strategy. BMJ Opinion. August 2021. https://blogs.bmj.com/bmj/2021/08/20/christina-pagel-schools-a-gaping-hole-in-the-englishcovid-strategy/

3 Pagel C, Squires A. Schools: still a gaping hole in the English covid strategy. BM/2021;375:n3149. doi: 10.1136/bmj.n3149. pmid: 34949597

4 Yahoo news. Record number of 6-17 year-olds being admitted to hospital with COVID. https://uk.news.yahoo.com/record-number-pupils-hospital-covid-175118701.html

5 Office for National Statistics. Prevalence of ongoing symptoms following coronavirus (COVID-19) infection in the UK: 6 January 2022. https://www.ons.gov.uk/peoplepopulationandcommunity/healthandsocialcare/conditionsanddiseases/bulletins/prevalenceofongoingsymptomsfollowingcoronaviruscovid19infectionintheuk/6january2022

6 Attendance in education and early years settings during the coronavirus (COVID-19) pandemic. https://explore-education-statistics.service.gov.uk/find-statistics/attendance-in-education-andearly-years-settings-during-the-coronavirus-covid-19-outbreak

7 Walter EB, Talaat KR, Sabharwal C, etalC4591007 Clinical Trial Group. Evaluation of the BNT162b2 Covid-19 Vaccine in Children 5 to 11 Years of Age. N Engl J Med 2022;386:35-46. doi: 10.1056/NEJMoa2116298. pmid: 34752019

8 The Advisory Committee on Immunization Practices' Interim Recommendation for Use of Pfizer-BioNTech COVID-19 Vaccine in Children Aged 5-11 Years - United States, November 2021 https://www.cdc.gov/mmwr/volumes/70/wr/mm7045e1.htm

9 Effectiveness of BNT162b2 (Pfizer-BioNTech) mRNA Vaccination Against Multisystem Inflammatory Syndrome in Children Among Persons Aged 12-18 Years - United States, July-December 2021 https://www.cdc.gov/mmwr/volumes/71/wr/mm7102e1.htm

10 Protecting your tamariki from COVID-19 https://covid19.govt.nz/assets/resources/vaccine-resources/COVID-19-vaccines_protecting-your-tamariki.pdf

11 Danish paediatricians question COVID-19 jab for children after Norwegian decision https://www.euractiv.com/section/politics/short_news/danish-paediatricians-question-covid-19jab-for-children-after-norwegian-decision/
12 UK regulator approves use of Pfizer/BioNTech vaccine in 5 to 11-year olds https://www.gov.uk/government/news/uk-regulator-approves-use-of-pfizerbiontech-vaccine-in5-to-11-year-olds

13 JCVI statement on COVID-19 vaccination of children and young people: 22 December 2021 https://www.gov.uk/government/publications/jcvi-update-on-advice-for-covid-19-vaccinationof-children-and-young-people/jcvi-statement-on-covid-19-vaccination-of-children-and-youngpeople-22-december-2021\#: :text=At\%20the\%20current\%20time\%2C\%20JCVI,in\%20a\%20 clinical\%20risk\%20group.

14 Mask Use and Ventilation Improvements to Reduce COVID-19 Incidence in Elementary Schools - Georgia. November 16-December 11, 2020 https://www.cdc.gov/mmwr/volumes/70/wr/mm7021e1.htm

15 Designing infectious disease resilience into school buildings through improvements to ventilation and air cleaning https://static1.squarespace.com/static/5ef3652ab722df1ffcb2ba5d/t/60a3d1251fcec67243e91119/1621348646314/Safe+Work+TF+Desigining+infectious+disease+resilience+April+2021.pdf

16 Government announcement on new mitigations to be brought into schools https://neu.org.uk/press-releases/government-announcement-new-mitigations-be-broughtschools

17 Office for National Statistics. Coronavirus (COVID-19) Infection Survey, characteristics of people testing positive for COVID-19, UK: 19 January 2022. https://www.ons.gov.uk/peoplepopulationandcommunity/healthandsocialcare/conditionsanddiseases/bulletins/coronaviruscovid19infectionsurveycharacteristicsofpeopletestingpositiveforcovid19uk/19january2022 